\title{
Aarno Averonat Avaliação do sistema nacional de vigilância da doença meningocócica: Brasil, 2007-2017
}

doi: 10.5123/S1679-49742019000300009

Evaluation of the national meningococcal disease surveillance system: Brazil, 2007-2017

Evaluación del sistema nacional de vigilancia de la enfermedad meningocócica:Brasil, 2007-2017

Igor Gonçalves Ribeiro' - (1) orcid.org/0000-0002-4971-9484
Jadher Percio' - (D) orcid.org/0000-0002-3641-8105
Camile de Moraes ${ }^{1}$ - (D) orcid.org/0000-0003-4789-0429
'Ministério da Saúde, Secretaria de Vigilância em Saúde, Brasília, DF, Brasil

\section{Resumo}

Objetivo: avaliar a vigilância da doença meningocócica (DM) no Brasil, em 2007-2017, segundo atributos. Métodos: estudo de avaliação dos atributos 'oportunidade', 'representatividade', 'simplicidade', 'flexibilidade', 'qualidade dos dados', 'aceitabilidade' e 'utilidade' do sistema, pautado nas diretrizes do Centers for Disease Control and Prevention dos Estados Unidos; utilizaram-se dados do Sistema de Informação de Agravos de Notificação (Sinan), com início dos sintomas em 2007-2017. Resultados: sistema complexo, com oito definições de caso e seis confirmações laboratoriais; flexível, com adequada descrição das mudanças epidemiológicas; de boa completitude de quimioprofilaxia, busca ativa e sorogrupagem; de aceitabilidade baixa, com quimioprofilaxia em menos de 70,0\% dos registros; oportuno, com investigação, encerramento e coleta de liquor excelentes; representativo, na descrição da DM no Brasil; útil, norteando adequadamente ações de controle. Conclusão: as diferentes apresentações clínicas da DM e o necessário manejo rápido interferem na aceitabilidade e na complexidade do sistema; este, porém, é útil nas análises epidemiológicas.

Palavras-chave: Infecções Meningocócicas; Avaliação de Programas e Projetos de Saúde; Serviços de Vigilância Epidemiológica; Sistemas de Informação.

Endereço para correspondência:

Igor Gonçalves Ribeiro - QRSW 6, Bloco B-8, Apto. 105, Edifício Fidji, Brasília, DF, Brasil. CEP: 70675-628

E-mail: igor.ribeiro@saude.gov.br; igorgribeiro@gmail.com 


\section{Introdução}

A doença meningocócica (DM) é uma infecção grave, causada pela bactéria Neisseria meningitidis (meningococo), com rápida evolução ao óbito se não tradada imediatamente - em menos de 24 horas -, e apresenta grande potencial epidêmico. ${ }^{1,2}$

De amplo espectro clínico, um indivíduo com DM pode variar desde a condição de portador são até a de meningocococemia fulminante, sendo as principais formas clínicas a meningite meningocócica (MM), a meningococcemia (MCC) e a meningite acompanhada de meningococcemia (MM+MCC). A MM, resultante de disseminação hematogênica, ocorre em cerca de 50\% dos pacientes infectados e é semelhante a outras formas de meningite purulenta. Já a MCC é caracterizada por início abrupto de febre e exantema petequial, que pode progredir para púrpura fulminante, ocorrendo em $5 \mathrm{a}$ $20 \%$ dos pacientes acometidos da enfermidade. ${ }^{1,3}$

\section{O sistema de vigilância epidemiológica da doença deve ser capaz de: produzir dados que contribuam para 0 conhecimento do perfil epidemiológico e etiológico da doença; monitorar a situação epidemiológica; detectar surtos precocemente; instituir medidas de prevenção e controle; e caracterizar os sorogrupos circulantes.}

A DM ocorre em todo o mundo, com marcantes diferenças em sua incidência segundo a região afetada e 0 sorogrupo mais frequente. ${ }^{4}$ No plano mundial, estima-se a ocorrência de 500 mil casos de DM por ano, com 50 mil óbitos, sendo o sorogrupo A o principal responsável devido, entre outros fatores, a sua elevada incidência no chamado 'Cinturão Africano da Meningite'. ${ }^{5}$ De acordo com a composição antigênica de sua cápsula polissacarídica, a $N$. meningitidis é classificada em 12 sorogrupos diferentes, sendo os sorogrupos A, B, C, Y, W e X os responsáveis por praticamente todos os casos de DM, infectando apenas humanos. ${ }^{4}$ No Brasil, a incidência média de DM entre os anos de 2007 e 2013 foi de 1,4 caso por 100 mil habitantes, sendo o sorogrupo $\mathrm{C}$ o principal responsável pelos casos. ${ }^{6}$
No país, a DM é endêmica, com ocorrência esporádica de surtos em territórios municipais. Seu comportamento também é sazonal, com aumento da incidência em períodos de inverno e decréscimo no verão, movimento observado mesmo em momentos epidêmicos. A doença também apresenta uma tendência secular, ou seja, a incidência ao longo do período aparenta ser semelhante à de períodos posteriores. ${ }^{7,8}$

Como medidas preventivas e de controle, são preconizadas a quimioprofilaxia com antibióticos e a vacinação. A quimioprofilaxia é recomendada para contatos próximos de um caso confirmado e deve ser realizada o mais rápido possível, para prevenção de casos secundários, os quais, apesar de raros, manifestam-se no prazo de 48 horas após o primeiro caso. ${ }^{9}$ A segunda medida, a vacinação, é a forma mais eficaz de prevenção da doença, sendo que as vacinas disponíveis são sorogrupo ou sorossubtipo-específicas. No Brasil, a vacina meningocócica C conjugada (MenC) foi implantada em 2010, para imunização de menores de 2 anos de idade, no calendário de vacinação da criança do Programa Nacional de Imunizações (PNI). Essa vacina também é utilizada para controle de surtos, na realização de bloqueios vacinais ou vacinação em massa. ${ }^{10,11}$

A DM no Brasil é uma doença de suma importância para a Saúde Pública, haja vista seu potencial de provocar surtos, motivo por que sua notificação é compulsória no território nacional desde a publicação da Portaria GM/MS no 1.271, de 6 de junho de 2014. Esta portaria também exige das autoridades sanitárias maior esforço no monitoramento e controle da infecção. A implantação de sistemas nacionais de vigilância objetiva garantir ações eficazes de manejo de doenças e agravos. A avaliação de um sistema de vigilância em saúde, portanto, busca garantir que seus objetivos fundamentais sejam devidamente cumpridos, com o uso racional e efetivo dos recursos públicos disponibilizados. ${ }^{12,13}$

Reconhecida a DM como um grave problema de Saúde Pública, torna-se necessária a avaliação sistemática do sistema de vigilância epidemiológica da doença. Esse sistema deve ser capaz de: produzir dados que contribuam para o conhecimento do perfil epidemiológico e etiológico da doença; monitorar a situação epidemiológica; detectar surtos precocemente; instituir medidas de prevenção e controle; e caracterizar os sorogrupos circulantes. ${ }^{7,9}$ 
0 presente estudo teve como objetivo avaliar a vigilância epidemiológica da DM entre 2007 e 2017, a partir dos atributos qualitativos, quantitativos e de utilidade do sistema.

\section{Métodos}

Foi elaborado um estudo de avaliação pautado nas diretrizes publicadas pelo Centers for Diserase Control and Prevention dos Estados Unidos no documento Updated Guidelines for Evaluating Public Health Surveillance Systems: recommendations from the guidelines working group,${ }^{14}$ com uma análise dos atributos quantitativos (oportunidade e representatividade) e qualitativos (simplicidade, flexibilidade, de qualidade dos dados e aceitabilidade) e a utilidade do sistema.

Utilizaram-se os dados do Sistema de Informação de Agravos de Notificação (Sinan) versão Net, com informações dos casos confirmados de DM cuja data de início dos sintomas situava-se entre os anos de 2007 e 2017. Essas informações foram aplicadas em cálculos de coeficiente de incidência por ano e por Unidade da Federação (UF), como também em medidas de porcentagem, segundo os critérios de avaliação de cada atributo avaliado. A última atualização do sistema e o recorte do banco de dados para o estudo foram feitos em maio de 2018.

Para a avaliação do atributo ‘simplicidade', foram utilizados dados descritivos do sistema de vigilância, incluindo as análises da definição de caso empregadas, dos métodos laboratoriais agregados e das medidas de controle pertinentes. A simplicidade foi analisada de forma subjetiva, e tomou-se como parâmetro a classificação do sistema como simples ou complexo.

0 atributo 'flexibilidade' foi avaliado a partir das mudanças sofridas nos coeficientes anuais de incidência da doença meningocócica, em consequência das novas intervenções implementadas na vigilância, no período estudado. No presente trabalho, constaram como novas intervenções a descentralização da técnica de polymerase chain reaction (PCR, ou reação em cadeia de polimerase) para os Laboratórios Centrais de Saúde Pública (Lacen) e a introdução da vacina meningocócica C conjugada (MenC) no Calendário Nacional de Vacinação, ambos processos iniciados no ano de 2010. Caso o sistema de vigilância da DM fosse capaz de captar e descrever adequadamente as mudanças dos coeficientes anuais de incidência da DM frente às intervenções descritas, ele seria classificado como flexível.

0 atributo 'qualidade dos dados' foi avaliado a partir da análise de completitude de determinados campos essenciais, obrigatórios e não obrigatórios, da ficha de notificação da DM. Esses campos foram escolhidos por refletirem aspectos essenciais da qualidade da intervenção da equipe de vigilância em saúde quando do surgimento de casos secundários de DM na comunidade, no sentido de se evitar a propagação da doença entre a população. Dados bem preenchidos significam que a intervenção da equipe de vigilância foi adequada. Dos campos obrigatórios, foi selecionado para análise o 'uso de quimioprofilaxia', e dos campos não obrigatórios, as variáveis 'vacinação contra MenC', 'contato com caso suspeito', 'caso secundário' e 'sorogrupo'. Para a análise do uso de quimioprofilaxia, foi considerada 'boa' somente a completitude média de $100 \%$ para o período analisado (2007 a 2017), pois o sistema de informação não salva os dados da notificação caso essa informação esteja ausente. Para as demais variáveis, não obrigatórias, os parâmetros estabelecidos foram: $\geq 90,0 \%$ para excelente; entre 80,0 e $89,9 \%$ para bom; entre 70,0 e $79,9 \%$ para regular; e $<70,0 \%$ para ruim. É mister lembrar que 0 sistema de informação aceita a notificação mesmo com a falta de dados das variáveis não obrigatórias, muito embora elas sejam essenciais à vigilância da DM, tanto na avaliação da qualidade da intervenção oferecida como na construção de indicadores epidemiológicos e operacionais, e por isso necessitem de uma boa porcentagem de preenchimento. ${ }^{15-17}$ Como critério de avaliação, três ou mais campos avaliados como 'bom' classificavam o sistema como de 'boa qualidade', e menos de três campos avaliados como 'bom', sistema de 'qualidade ruim'.

0 atributo ‘aceitabilidade' foi avaliado pela oportunidade média - ao longo do período de estudo - da quimioprofilaxia dos contatos próximos ao suspeito de DM, que deve ser feita em até 48 horas da data de notificação. Portanto, foram analisados os campos 'data da notificação' e 'data de realização da quimioprofilaxia' da ficha de investigação, visando estimar o tempo decorrido entre a notificação e os procedimentos de quimioprofilaxia dos contatos. A quimioprofilaxia dos contactantes pressupõe, necessariamente, uma série de medidas a serem tomadas pelas equipes de saúde: 
investigação do total de contatos a serem medicados; controle de estoque e de utilização da medicação quimioprofilática; monitoramento de casos secundários ou com efeitos colaterais medicamentosos; e busca ativa de comunicantes faltosos. 0 devido registro da intervenção na ficha de notificação revela a oportunidade de quimioprofilaxia, sendo um importante indicador da disposição dos profissionais de saúde em desenvolver com perícia as atividades preconizadas pela vigilância da DM, ao mesmo tempo que descreve a aceitabilidade do sistema por esses profissionais. ${ }^{15-17}$ Como critério avaliativo, o sistema foi considerado de alta aceitabilidade caso a oportunidade de quimioprofilaxia média no período estudado fosse maior ou igual a 70,0\%, tendo em vista que nem sempre será possível um atendimento oportuno dadas as dificuldades operacionais de busca ativa (zonas remotas ou de acesso dificultado), de profissionais envolvidos (não treinados ou em quantidade insuficiente) e tecnológicas (falta de insumos medicamentosos ou de kits para exames laboratoriais) ${ }^{6,8}$

$\mathrm{Na}$ análise do atributo 'oportunidade', foram observados:

a) tempo decorrido entre $o$ início dos sintomas e a internação hospitalar do caso (até 24 horas);

b) tempo entre a internação hospitalar e a notificação do caso à vigilância (até 24 horas);

d) tempo entre a notificação e o início da investigação (até 24 horas);

c) tempo entre a internação e a punção lombar, para os casos que realizaram coleta de líquido cefalorraquidiano (LCR, também conhecido como líquor) (até 24 horas);

e) tempo entre a notificação e a realização de quimioprofilaxia para os contatos próximos (até 48 horas); $\mathrm{e}$

f) tempo entre a notificação e o encerramento do caso (até 60 dias).

Como parâmetros de análise da 'oportunidade' do sistema, foram consideradas as porcentagens médias calculadas no período de estudo, sendo essa oportunidade assim definida: excelente, quando maior ou igual a $90,0 \%$; boa, entre 70,0 e $89,9 \%$; regular, entre 50,0 e $69,9 \%$; e ruim, quando menor que $50,0 \%$. Como critérios avaliativos, considerou-se o sistema oportuno quando os campos avaliados como 'bom' somavam três ou mais. Do contrário, eram considerados não oportunos, conforme prevê o caderno de avaliação da qualidade de dados de sistemas de vigilância das meningites. ${ }^{15-17}$

0 atributo 'representatividade' foi avaliado a partir da capacidade do sistema em descrever, de forma precisa (tempo, lugar e pessoa) o evento DM no Brasil a partir dos dados presentes no Sinan no período de estudo definido, com enfoque nos cálculos de coeficiente de incidência da DM estratificados por ano, UF, região administrativa e faixas etárias mais acometidas.

0 atributo 'utilidade' do sistema foi avaliado de acordo com sua contribuição de indicadores eficazes na descrição da magnitude da DM no Brasil, determinando e orientando as medidas de controle e monitoramento. ${ }^{14}$ Conforme o Guia de Vigilância em Saúde, publicado pelo Ministério da Saúde em 2017, constam como objetivos do sistema de vigilância da DM: ${ }^{?}$

1) Monitorar a situação epidemiológica da doença meningocócica no país.

2) Detectar surtos precocemente.

3) Orientar a utilização e avaliar a efetividade das medidas de prevenção e controle.

4) Monitorar a prevalência dos sorogrupos e sorotipos de N. meningitidis circulantes.

5) Monitorar o perfil da resistência bacteriana das cepas de $N$. meningitidis identificadas.

6) Produzir e disseminar informações epidemiológicas.

Caso o sistema de vigilância da DM seja capaz de fornecer dados epidemiológicos pertinentes ao cumprimento desses objetivos, ele será considerado útil.

Para a análise e processamento dos dados, foram utilizados os programas Tabwin ${ }^{\circledR} 3.6 \mathrm{~b}$, Epi Info ${ }^{\mathrm{TM}}$

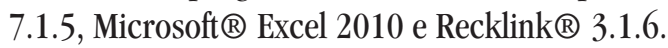

Por se tratar da avaliação de uma vigilância epidemiológica instituída a partir da análise de dados secundários, constantes de um banco nacional não nominal, o estudo foi dispensado de submissão a um Comitê de Ética em Pesquisa, com a devida observação dos aspectos éticos constantes em duas Resoluções do Conselho Nacional de Saúde: CNS no 466, de 12 de dezembro de 2012; e CNS n ${ }^{\circ} 510$, de 7 de abril de 2016. 0 acesso à base de dados foi possível mediante consentimento institucional. Os resultados do estudo foram agregados, e são apresentados a seguir.

\section{Resultados}

Foram estudados 23.930 casos confirmados de DM no Brasil, com início dos sintomas entre 2007 e 
2017. 0 sistema utiliza três definições de caso suspeito, pautadas em critérios clínicos de avaliação, quatro definições de caso confirmado, pautadas em critérios clínico-laboratoriais, e uma definição de caso descartado, pautada em critérios de exclusão a partir dos casos confirmados (se o quadro suspeito não cumpre os critérios de confirmação, ele é automaticamente descartado para DM). ${ }^{14}$

Os casos suspeitos de DM também possuem seis modelos diferentes de confirmação laboratorial (quimiocitológico, bacterioscopia, contraimunoeletroforese, aglutinação pelo látex, PCR ou cultura), majoritariamente desenvolvidos por serviços de saúde municipais e estaduais.

As medidas de controle de novos casos são dependentes de medicamentos e imunobiológicos, sendo utilizada a quimioprofilaxia de 48 horas em contatos de casos esporádicos; em casos de surto de DM, além da quimioprofilaxia, faz-se bloqueio vacinal.

A vigilância epidemiológica da DM possui alta sensibilidade para captação de casos, a partir do uso de oito definições de caso, acompanhada de seis modelos diferentes de confirmação laboratorial, e com um sistema de medidas de controle e prevenção dependente de medicamentos e imunobiológicos. Por essas características, a vigilância epidemiológica da DM foi considerada complexa.

A partir do ano de 2010, a introdução da MenC no calendário vacinal básico brasileiro promoveu a redução da incidência da DM sorogrupo $C$ na população, e a descentralização da técnica de PCR para os estados promoveu a redução na incidência de DM sem identificação de sorogrupo (Figura 1). Como o sistema de vigilância epidemiológica foi capaz de descrever essas mudanças a partir das intervenções promovidas, ele foi considerado flexível.

A Tabela 1 mostra que a completitude do 'uso de quimioprofilaxia' foi boa em todo o período analisado. Mostraram-se excelentes as completitudes para 'contato com suspeito' e 'sorogrupo', regular para 'vacinação com MenC' e ruim para 'caso secundário'. Como três de cinco campos tiveram completitude avaliada como boa ou excelente, a qualidade dos dados do sistema de vigilância da DM foi considerada alta.

Na Tabela 2, contatou-se uma porcentagem média de $56,3 \%$ de registros com quimioprofilaxia oportuna

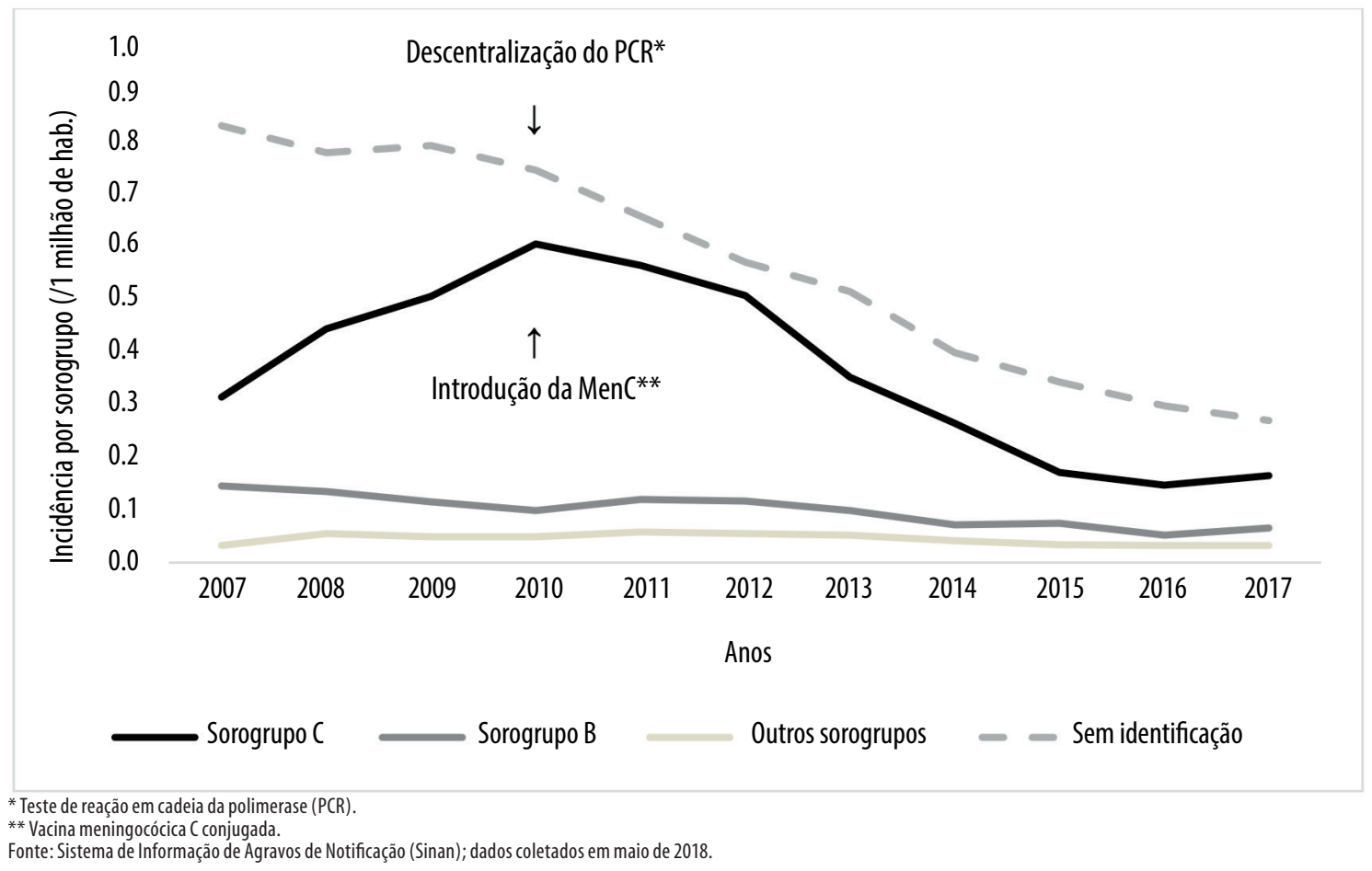

Figura 1 - Incidência da doença meningocócica por sorogrupo, Brasil, 2007-2017 
dos contatos (até 48h dos sintomas do caso suspeito); em nenhum dos anos avaliados o registro de quimioprofilaxia oportuna ultrapassou a taxa de $60,0 \%$. Como a quimioprofilaxia foi oportuna em menos de $70,0 \%$ dos registros, a aceitabilidade do sistema foi considerada baixa.

As taxas médias das oportunidades de investigação (96,6\%) e encerramento $(93,5 \%)$ foram excelentes, a de coleta de LCR $(87,7 \%)$ foi boa, e as oportunidades de notificação $(68,3 \%)$, atendimento $(58,1 \%)$ e quimioprofilaxia $(56,3 \%)$ foram regulares. Portanto, o sistema de vigilância epidemiológica da DM foi considerado oportuno (Tabela 2).

A Figura 2 descreve que no Brasil, no período de 2007 a 2017, a maior incidência de casos de DM ocorreu nas faixas etárias menores de 5 anos, particularmente nos menores de 1 ano. Observou- -se progressiva redução da incidência a partir de 2010, pautada na hipótese da redução de casos decorrente da introdução da MenC no Calendário Nacional de Vacinação.

A Figura 3 demonstra que no Brasil, entre os anos de 2007 e 2010, as incidências médias de DM para o período em questão estavam próximas ou acima da taxa de 1 caso/100 mil hab., com distribuição homogênea em todo o território nacional, tendendo a uma maior concentração na região litorânea do país. Entre os anos de 2011 e 2014, as incidências médias mostraram-se reduzidas para taxas menores que $1 \mathrm{caso} / 100 \mathrm{mil}$ hab., embora estados como São Paulo, Rio de Janeiro e Pernambuco ainda apresentassem taxas médias de incidência superiores. No período de 2015 a 2017, o país apresentou incidências médias menores que 0,5 caso/100 mil hab. em seu território, principalmente

\section{Tabela 1 - Completitude de variáveis obrigatórias e não obrigatórias do sistema de vigilância epidemiológica da doença meningocócica, Brasil, 2007-2017}

\begin{tabular}{|c|c|c|c|c|c|c|c|c|c|c|c|c|c|}
\hline \multirow{2}{*}{ Variáveis (campos) } & \multicolumn{13}{|c|}{ Completitude (\%) } \\
\hline & 2007 & 2008 & 2009 & 2010 & 2011 & 2012 & 2013 & 2014 & 2015 & 2016 & 2017 & Média & Avaliação \\
\hline \multicolumn{14}{|l|}{ Obrigatórias } \\
\hline Uso de quimioprofilaxia & 100,0 & 100,0 & 100,0 & 100,0 & 100,0 & 100,0 & 100,0 & 100,0 & 100,0 & 100,0 & 100,0 & 100,0 & Boa \\
\hline \multicolumn{14}{|l|}{ Não obrigatórias } \\
\hline Vacinação com Menc ${ }^{a}$ & 75,6 & 74,8 & 74,9 & 76,9 & 76,2 & 77,5 & 76,0 & 79,1 & 80,9 & 81,1 & 80,7 & 77,6 & Regular \\
\hline Contato com suspeito & 93,7 & 93,6 & 93,7 & 92,7 & 92,0 & 93,3 & 92,6 & 93,7 & 94,5 & 95,8 & 94,2 & 93,6 & Excelente \\
\hline Caso secundário & 3,2 & 2,2 & 2,6 & 2,9 & 2,5 & 3,1 & 1,8 & 2,4 & 3,0 & 2,3 & 2,1 & 2,6 & Ruim \\
\hline Sorogrupo & 100,0 & 100,0 & 100,0 & 100,0 & 100,0 & 100,0 & 100,0 & 100,0 & 100,0 & 100,0 & 100,0 & 100,0 & Excelente \\
\hline
\end{tabular}

a) Vacina meningocócica C conjugada.

Fonte:Sistema de Informação de Agravos de Notificação (Sinan); dados coletados em maio de 2018.

\section{Tabela 2 - Oportunidades avaliadas da vigilância epidemiológica da doença meningocócica, Brasil, 2007-2017}

\begin{tabular}{|c|c|c|c|c|c|c|c|c|c|c|c|c|c|}
\hline Oportunidade & 2007 & 2008 & 2009 & 2010 & 2011 & 2012 & 2013 & 2014 & 2015 & 2016 & 2017 & $\begin{array}{c}\text { Média } \\
\text { 2007-2017 }\end{array}$ & Classificação \\
\hline Notificação $\leq 24 \mathrm{~h}$ & 67,0 & 67,9 & 67,8 & 69,1 & 69,8 & 70,7 & 70,6 & 68,0 & 67,9 & 66,8 & 65,3 & 68,3 & Regular \\
\hline Atendimento $\leq 24 \mathrm{~h}$ & 61,1 & 59,1 & 62,2 & 58,9 & 60,4 & 57,1 & 54,6 & 58,0 & 55,4 & 57,9 & 54,7 & 58,1 & Regular \\
\hline $\begin{array}{l}\text { Investigação } \\
\text { epidemiológica } \leq 24 \mathrm{~h}\end{array}$ & 95,8 & 96,4 & 96,0 & 96,2 & 97,0 & 97,3 & 97,1 & 97,0 & 95,9 & 97,7 & 96,6 & 96,6 & Excelente \\
\hline Coleta de $L C R^{a} \leq 24 h$ & 88,2 & 89,1 & 87,3 & 89,1 & 87,7 & 88,6 & 88,5 & 87,6 & 85,5 & 86,9 & 86,7 & 87,7 & Boa \\
\hline Quimioprofilaxia $\leq 48 \mathrm{~h}$ & 53,9 & 54,9 & 56,5 & 59,8 & 57,8 & 58,5 & 59,8 & 54,2 & 55,1 & 55,9 & 52,7 & 56,3 & Regular \\
\hline Encerramento até 60 dias & 86,5 & 87,9 & 93,5 & 95,0 & 94,3 & 94,8 & 96,1 & 95,6 & 95,2 & 93,9 & 95,5 & 93,5 & Excelente \\
\hline
\end{tabular}

a) LCR: líquido cefalorraquidiano (liquor)

Fonte: Sistema de Informação de Agravos de Notificação (Sinan); dados coletados em maio de 2018. 


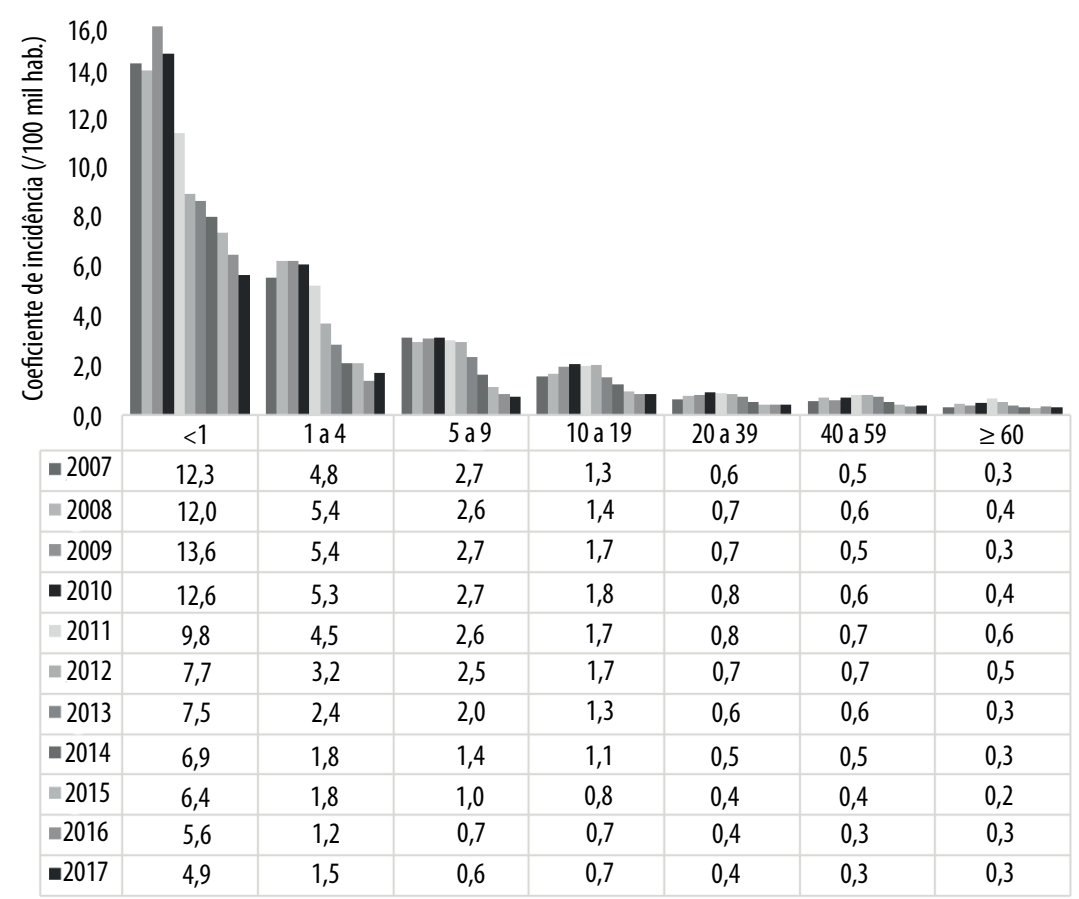

Fonte: Sistema de Informação de Agravos de Notificação (Sinan); dados coletados em maio de 2018.

Figura 2 - Incidência da doença meningocócica por faixa etária, Brasil, 2007-2017



Fonte: Sistema de Informação de Agravos de Notificação (Sinan); dados coletados em maio de 2018.

Figura 3 - Incidência da doença meningocócica por Unidade da Federação, Brasil, 2007-2017 
nas regiões Norte, Nordeste e Centro-Oeste; no mesmo período, os estados do Rio de Janeiro e de São Paulo apresentaram incidências médias inferiores a 1 caso/100 mil hab.

Ao permitir a descrição no tempo, lugar e pessoa do evento DM no Brasil, o sistema de vigilância epidemiológica da doença foi considerado representativo.

Por fim, quanto ao atributo 'utilidade' do sistema', verificou-se que a vigilância da DM é capaz de fornecer indicadores importantes e condizentes com os objetivos preconizados, apontando tendências epidemiológicas com suas devidas especificidades, especialmente por sorogrupos e faixas etárias acometidas.

Os coeficientes de incidência apresentados neste estudo exemplificam que o sistema é capaz de fornecer dados específicos por sorogrupo da $N$. meningitidis, informando não apenas a tendência de magnitude da doença segundo sorogrupagem, senão também orientando as devidas formas de controle - neste caso em especial, a priorização no Brasil do uso da vacina meningocócica $\mathrm{C}$ conjugada como principal ação preventiva de imunização, visto que a maioria dos casos são acometidos pela DM sorogrupo C. . $^{4,8,10}$

Os coeficientes de incidência específicos por faixa etária, calculados neste estudo, também mostram que o sistema é capaz de informar a magnitude e a tendência da doença meningocócica por faixas etárias acometidas; os menores de 5 anos foram os mais afetados e, por conseguinte, a faixa etária definida para imunização contra DM no calendário de vacinação do PNI. ${ }^{10}$ Como o sistema de vigilância da doença meningocócica é capaz de fornecer dados epidemiológicos eficazes e nortear ações de prevenção e controle efetivas, ele foi considerado útil.

\section{Discussão}

O sistema de vigilância epidemiológica da DM foi considerado útil, complexo, flexível, com boa qualidade de dados, baixa aceitabilidade, representativo, e com oportunidades variando entre excelente e regular, de acordo com o tipo analisado.

A complexidade do sistema de vigilância para confirmação diagnóstica de um caso de doença meningocócica é resultado direto da dinâmica do quadro de 'meningite'. Esta, por ser uma síndrome clínica, perpassa diversas apresentações clínicas e possíveis etiologias, exigindo da equipe de saúde a devida acurácia na intervenção para definição da etiologia causal. ${ }^{1,3,8}$ A maior sensibilidade da definição de caso na captação de casos de meningite, por sua vez, é necessária porque a síndrome neurológica é rara e grave, exige atenção em saúde de urgência para seu tratamento, além da devida busca ativa de possíveis casos secundários. ${ }^{1,3,8,17}$

Todavia, a mesma complexidade do sistema, que impõe dificuldades para sua operacionalização profissional, interfere em sua aceitabilidade pelos mesmos profissionais de saúde. Um grande esforço profissional é necessário na captação, investigação e manejo quimioprofilático dos casos. É possível que essas ações nem sempre sejam realizadas em sua plenitude e com a qualidade esperada dos profissionais de saúde lotados nos serviços da ponta do sistema de saúde. . $^{1,3,8,17}$

A boa flexibilidade do sistema de vigilância da DM na identificação de efeitos e mudanças de incidência dos sorogrupos da DM, a partir da implantação da MenC na vacinação pública, permitiu identificar que esse sistema é capaz de perceber o efeito de novos procedimentos ou métodos diagnósticos quando introduzidos, dotado da habilidade de descrever com segurança novas tendências da dinâmica da DM na população brasileira. Outro fator importante, a corroborar a segurança das análises feitas a partir do banco de dados de DM, é a boa qualidade dos dados identificada neste estudo. ${ }^{6,13,17}$

A boa representatividade do sistema também é outro fator positivo, no que tange ao monitoramento e apontamento de novas tendências pertinentes à dinâmica da DM. 0 sistema detecta bem as mudanças no padrão epidemiológico da doença no país. ${ }^{13,8}$ Vale ressaltar que uma das principais contribuições do sistema à análise de tendência da DM no Brasil foi o monitoramento da incidência da DM a partir da introdução da MenC no calendário nacional de vacinação. ${ }^{4,10}$

A análise das oportunidades do sistema de vigilância da doença meningocócica conseguiu demonstrar que as ações da vigilância devem ser avaliadas a partir da data de notificação dos casos e não pela data de início dos sintomas, visto que todo o processo se desencadeia desde a notificação de um caso suspeito internado em hospital ou pronto atendimento. Até então, a vigilância epidemiológica local não possuía informações suficientes para dar início às atividades de controle. Além disso, a oportunidade das ações, ou seja, a celeridade com que o tratamento e o controle são realizados, depende diretamente da oportunidade de notificação do caso suspeito de DM, fazendo da oportunidade o atributo mais importante do sistema. ${ }^{3,5-7}$

Em relação às limitações do estudo, pode-se afirmar que os parâmetros para mensuração e classificação dos atributos analisados são subjetivos, e, nesse 
sentido, podem acarretar subestimação ou superestimação dos resultados por parte do pesquisador que analisa os dados.

O sistema de vigilância da doença meningocócica no Brasil é útil para a análise de tendência e monitoramento do perfil da doença no Brasil. Não obstante, é necessário um constante monitoramento e treinamento dos profissionais de saúde, principalmente daqueles que trabalham na atenção clínica à doença meningocócica, capacitando-os a superar as dificuldades provocadas pela complexidade natural de um sistema de vigilância fundamentado em uma síndrome clínica, fortemente dependente da disponibilidade de profissionais, medicamentos e exames laboratoriais.

\section{Referências}

1. Rosenstein NE, Perkins BA, Stephens DS, Popovic T, Hughes JM. Meningococcal disease. $\mathrm{N}$ Engl J Med [Internet]. 2001 May [cited 2019 Jun 10];344(18):1378-88. Available from: https://www.nejm.org/doi/full/10.1056/ NEJM200105033441807?url_ver=Z39.88$2003 \&$ rfr_id=ori:rid:crossref.org\&rfr dat $=$ cr_pub\%3dpubmed. doi: 10.105 $\overline{6} /$ NEJM200105033441807

2. Branco RG, Amoretti CF, Tasker RC. Meningococcal disease and meningitis. J Pediatr (Rio J) [Internet]. 2007 May [cited 2019 Jun 10];83(2 Suppl):S46-53. Available from: http://www.scielo.br/pdf/jped/v83n2s0/ en_a06v83n2s0.pdf. doi: 10.1590/S002175572007000300006

3. Nacional Institute for Health and Care Excellence (NICE). Meningitis (bacterial) and meningococcal septicaemia in under 16s: recognition, diagnosis and management [Internet]. Londres: NICE; 2015 [cited 2019 Jun 10]. Available from: nice.org.uk/ guidance/cg102

4. Sáfadi MP, González-Ayala S, Jäkel A, Wieffer $\mathrm{H}$, Moreno C, Vyse A. The epidemiology of meningococcal disease in Latin America 1945-2010: an unpredictable and changing landscape. Epidemiol Infect [Internet]. 2012 Mar [cited 2019 Jun 10];141(3):447-58. Available from: https://www.ncbi.nlm.nih.gov/ pmc/articles/PMC3566594/. doi: 10.1017/ S0950268812001689

\section{Contribuição dos autores}

Ribeiro IG, Percio J e Moraes C participaram da concepção e delineamento do estudo. Ribeiro IG e Percio J participaram da coleta dos dados, análise e interpretação dos resultados. Ribeiro IG e Percio $\mathrm{J}$ redigiram a versão preliminar do manuscrito. Moraes C colaborou na revisão crítica relevante do conteúdo intelectual do manuscrito. Todos os autores aprovaram a versão final e declaram-se responsáveis pelo conteúdo integral do artigo, garantindo sua precisão e integridade.

5. Santos ML, Ruffino-Netto A. Doença meningocócica: situação epidemiológica no Município de Manaus, Amazonas, Brasil, 1998/2002. Cad Saúde Pública [Internet]. 2005 maio-jun [citado 2019 jun 10];21(3):8239. Disponível em: http://www.scielo.br/pdf/ csp/v21n3/16.pdf. doi: 10.1590/S0102311X2005000300016

6. Moraes C. Avaliação do sistema de vigilância epidemiológica da meningite, com ênfase em meningites bacterianas não-especificadas, Brasil, 2001 a 2006. [trabalho de conclusão de curso]. Brasília (DF): Episus; 2007.

7. Moraes JC, Barata RB. A doença meningocócica em São Paulo, Brasil, no século XX: características epidemiológicas. Cad Saúde Pública [Internet]. 2005 set-out [citado 2019 jun 10];21(5):1458-71. Disponível em: http:// www.scielo.br/pdf/csp/v21n5/19.pdf. doi: 10.1590/S0102-311X2005000500019

8. Barroso DE, Carvalho DM, Nogueira SA, Solari CA. Doença meningocócica: epidemiologia e controle dos casos secundários. Rev Saúde Pública [Internet]. 1998 fev [citado 2019 jun 10];32(1):89-97. Disponível em: http://www. scielo.br/pdf/rsp/v32n1/2381.pdf. doi: 10.1590/ S0034-89101998000100014

9. Ministério da Saúde (BR). Secretaria de Vigilância em Saúde. Guia de Vigilância em Saúde [Internet]. 8. ed. Brasília: Ministério da Saúde; 
2017 [citado 2019 jun 10]. v. 1. Disponível em: http://bvsms.saude.gov.br/bvs/publicacoes/ guia_vigilancia_saude_volume_1.pdf

10. Laval CAB, Pimenta FC, Andrade JG, Andrade SS, Andrade ALSS. Progress towards meningitis prevention in the conjugate vaccines era. Braz J Infect Dis [Internet]. 2003 Oct [cited 2019 Jun 10];7 (5):315-24. Available from: http://www. scielo.br/pdf/bjid/v7n5/18581.pdf. doi: 10.1590/ S1413-86702003000500006

11. Cardoso CW, Pinto LLS, Reis MG, Flannery $\mathrm{B}$, Reis JN. Impact of vaccination during an epidemic of serogroup C meningococcal disease in Salvador, Brazil. Vaccine [Internet]. $2012 \mathrm{Aug}$ [cited 2019 Jun 10];30(37):5541-6. Available from: https:// www.sciencedirect.com/science/article/pii/ S0264410X12009103?via\%3Dihub. doi: 10.1016/j.vaccine.2012.06.044

12. Cassia NG, Carvalhanas T. Meningites no município de São Paulo, com ênfase para doença meningocócica. CVE SP. 2012;9(97):525.

13. Fundação Instituto Oswaldo Cruz. Diretrizes para avaliação de sistemas de vigilância epidemiológica. Rio de Janeiro: Fundação Instituto Oswaldo Cruz; 2001.

14. Armstrong G, Birkhead GS, Horan JM, Herrera G, Lee LM, Milstein RL, Centers for Disease Control and Prevention, et al. Updated guidelines for evaluating public health surveillance systems: recommendations from the guidelines working group. MMWR. $2001 \mathrm{Jul}$ [cited 2019 Jun 10];50(RR-13):1-35. Available from: https://www.cdc.gov/mmwr/preview/ mmwrhtml/rr5013a1.htm

15. Organização Pan-Americana da Saúde. Organização Mundial da Saúde. Informe regional de SIREVA II 2000 - 2012 [Internet]. Washington (D.C.): Organização Pan-Americana da Saúde; 2011 [citado 2019 jun 10]. Disponível em: http://www.paho.org/hq/index. php?option=com_content\&view=category\&layo ut $=$ blog\&id $=3609 \&$ Itemid $=3953$

16. Ministério da Saúde (BR). Secretaria de Vigilância em Saúde. Roteiro para uso do Sinan-NET, análise da qualidade da base de dados e cálculo de indicadores epidemiológicos e operacionais: meningite [Internet]. Brasília: Ministério da Saúde; 2008 [citado 2019 jun 10]. Disponível em: http://www.saude.ba.gov. br/wp-content/uploads/2017/12/Caderno-deanalise-EXANT.pdf

17. Moraes, G. H.; Carvalho, ML. ; Monteiro, L. ; Brondi, LM. . Vigilância Epidemiológica das Meningites no Brasil. 2001. Disponível em: http://portalarquivos2.saude.gov.br/images/ pdf/2016/outubro/18/Revista-MemoriasEPISUS-10-anos.pdf 


\begin{abstract}
Objective: to evaluate meningococcal disease (MD) surveillance from 2007-2017, according to its attributes. Methods: this was a descriptive study of the 'timeliness', 'representativeness', 'simplicity', 'flexibility', 'data quality', 'acceptability' and 'usefulness' attributes of the system, based on Centers for Disease Control and Prevention guidelines; we used National Notifiable Diseases Information System (SINAN) data, with onset of symptoms between 2007-2017. Results: the system was found to be complex with eight case definitions and six laboratory confirmations; flexible, with adequate description of epidemiological changes; good chemoprophylaxis, active tracing and serogrouping completeness; low acceptability with chemoprophylaxis found in less than $70.0 \%$ of records; timely, with excellent investigation, closure and collection of cerebrospinal fluid; representative, in its description of MD in Brazil; useful, adequately guiding control actions. Conclusion: different clinical presentations of MD and the need for rapid case management interfere with the system's acceptability and complexity; the latter, however, is useful for epidemiological analysis.
\end{abstract}

Keywords: Meningococcal Infections; Program Evaluation; Epidemiologic Surveillance Services; Information Systems.

\section{Resumen}

Objetivo: evaluar la vigilancia de la enfermedad meningocócica (EM) entre 2007-2017 según los atributos. Métodos: estudio de evaluación de los atributos "oportunidad", "representatividad", "simplicidad", "flexibilidad", "calidad de los datos", "aceptabilidad" y "utilidad del sistema", basados en directrices del Centers for Disease Control and Prevention de Estados Unidos; se utilizaron datos del Sistema de Notificación de Agravamientos de Notificación (Sinan), con inicio de los síntomas entre 2007-2017. Resultados: sistema complejo con ocho definiciones de caso y seis confirmaciones de laboratorio; flexible, con adecuada descripción de cambios epidemiológicos; buena completitud de quimioprofilaxis, búsqueda activa y serogrupo; aceptabilidad baja con quimioprofilaxis registrada en menos del 70,0\% de los registros; sistema oportuno, con investigación, cierre e colecta de líquido cefalorraquídeo excelente; representativo, con la debida descripción de la EM en Brasil; es útil, orientando adecuadamente las acciones de control. Conclusión: las diferentes presentaciones clinicas de la EM y el necesario manejo rápido interfieren en la aceptabilidad y complejidad del sistema, pero éste es útil para los análisis epidemiológicos.

Palabras clave: Infecciones Meningocócicas; Evaluació n de Programas y Proyectos de Salud; Servicios de Vigilancia Epidemiológica; Sistemas de Información.

Recebido em 03/10/2018

Aprovado em 10/05/2019 